\title{
Methods of Flushing of Sewage Sludge Collected on the Bottom of a Retention Chamber
}

\author{
Robert Malmur', Maciej Mrowiec ${ }^{1}$ \\ 1 Czestochowa University of Technology, Faculty of Infrastructure and Environment, Institute of Environmental \\ Engineering, ul. Brzeźnicka 60a, 42-200 Częstochowa, Poland \\ * Corresponding author's e-mail: rmalmur@is.pcz.czest.pl
}

\begin{abstract}
This paper presents new achievements in the field of designing the gravitation and gravitation-underpressure chamber for bottom flushing in the detention chamber immediately after its emptying from the accumulated sewage. Temporary accumulation of the sewage in the detention chamber of the reservoir causes partial sedimentation of the solids suspended in the liquid. The location of the flushing chamber at the maximal level of filling with sewage in the retention chamber substantially improves the effectiveness of flushing of the bottom of the retention chamber with the stream of sewage that is discharged from the flushing chamber. An opportunity for effective flushing of the sludge that remains on the bottom of a detention chamber represents an important operation which is essential for reliable functioning of retention reservoirs within sewerage systems.
\end{abstract}

Keywords: drainage system, retention, sewage, sewage reservoirs, transfer reservoirs

\section{INTRODUCTION}

Retention reservoirs represent an inherent element of contemporary sewerage systems and, depending on the purpose, may perform various functions at individual stages of sewage transport. Their basic role is to collect and temporarily store specific volumes of sewage in order to reduce the intensity of outflow to the system below the reservoir. Normal operation of the sewerage system does not assume a technological parameter which would manage short but substantial volumes of sewage. Therefore, the economically justified need (or even the necessity) to use retention reservoirs arises [Wolski et al., 2011]. During accumulation of sewage in the retention chamber, each retention reservoir, especially in the stormwater system and the combined sewer system, acts as a settling tank and accumulates sludge transported with sewage to the reservoir on its bottom [Ociepa et al., 2015; Zawieja et al., 2013].

Preventing collection of sewage sludge on the bottom of retention chambers is one of the basic functional problems of sewerage systems.
The use of an effective flushing method to remove the sludge from the retention chambers of the reservoir following their emptying should be planned at each stage of the technological design. Neglecting the activities aimed to prevent collecting of the sludge on the bottom of retention chambers of the reservoir leads not only to collecting excessive amount of sludge but also makes removing the sludge more difficult over the longer period of use. Therefore, this operation is required and more justified if flushing has to be performed automatically without direct or indirect human intervention.

\section{METHODS}

The easiest method to flush the sewage sludge from the bottom of a retention chamber involves pressure flushing with the stream of water (sometimes stream of sewage) using the WUKO special-purpose vehicle. However, with many-year perspective of the use of reservoir, this method of emptying is uneconomical and it is critical to 
perform this process automatically, without direct or indirect human intervention.

If the sewage flows through the entire length of the chamber or in the cases of the SIMPLEX conventional gravitational reservoir, the suggested solution is to employ the system of parallel troughs with semicircular, triangular or trapezoidal cross-section. The multi-chamber retention reservoirs with the gravitational hydraulic system presented in many publications [Deska et al., 2016; Dziopak, 1990] have a flow chamber with insignificant volume and are connected to the retention chambers with an overflow edge. In such cases, a part of the suspensions that are transferred to the retention chamber is settled on the bottom through the sedimentation processes, although the time of sewage storage is around several minutes. The automated hydraulic transport of sewage sludge outside the chamber is impossible in the process of reservoir emptying. After the total emptying of the reservoir and drying the bottom of the retention chamber, the sludge forms a hard crust which cannot be removed using individual cycles of filling and emptying of the reservoir. This is conducive to the formation of individual layers of sludge and increases the difficulty of removal.

Out of the bottom flushing systems used in practice, the most popular solutions are: a) Capsizable flushing units located at the end of the retention chamber. Flushing of the bottom is performed with the emptied chamber of the reservoir through a fast rotation of the flushing unit and outflow of the whole volume (from 300 to $1500 \mathrm{dm}^{3}$ ) of the fluid to the bottom of the chamber (Fig. 1a). The stream of the fluid flowing from a substantial height has an energy that ensures efficient cleaning of the bottom from the sludge. After emptying from the fluid, the flushing unit returns to the initial position. The filling of the flushing unit can occur, as previously, in two ways. In the first variant, the flushing unit is filled with the sewage flowing to the retention chamber. In the second variant, the flushing unit is filled by means of the pump that supplies pure water or sewage from the reservoir.

b) Flushing chambers, the adequate content of which is separated from the total retention volume of the reservoir (Fig. 1b), operate in two basic versions. In the first version, the chamber is filled gravitationally through the overflow edge whereas in the second, the chamber is filled usually using the negative pressure by reducing the pressure of air closed and cut-off from the atmosphere in the chamber.

c) Systems using the pressure pumps (Fig. 1c) which are mounted whenever the need for flush-
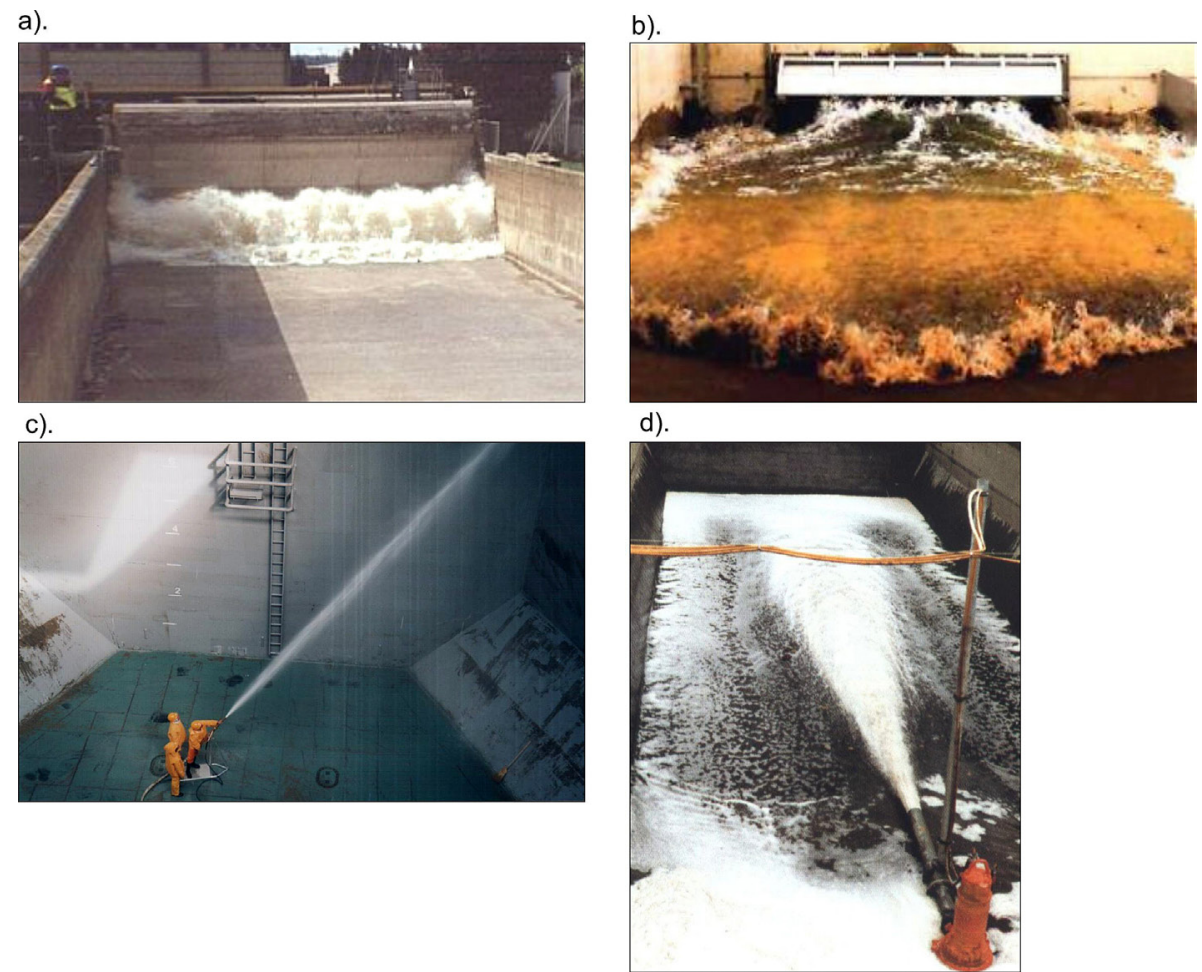

Fig. 1. Examples of flushing of the bottom of the chambers of retention reservoirs a) using the submersible pumps, b) with capsizable flushing unit, c) with separated flushing unit 
ing the reservoir arises. Using the pumps controlled by an operator, the reservoir is flushed (both its side walls and the bottom). During the operation, the reservoir is unused, whereas the retention chamber is entirely emptied.

d) Systems using the submersible pumps located at the end of the retention chamber at the wall opposite to the outlet hole (Fig. 1d). Pumps are started after a total emptying of the retention chamber and flush its bottom with the high velocity stream. The flushing fluid can be provided by the sewage stopped in the depression of the reservoir or pure water supplied from the external water supply system.

\section{DESIGN OF THE FLUSHING RESERVOIR}

The flushing reservoir is always located on the opposite side with respect to the outflow collector. The reservoir works based on the principle of negative pressure and filling the container occurs through the bottom drain trap hole, while

a)

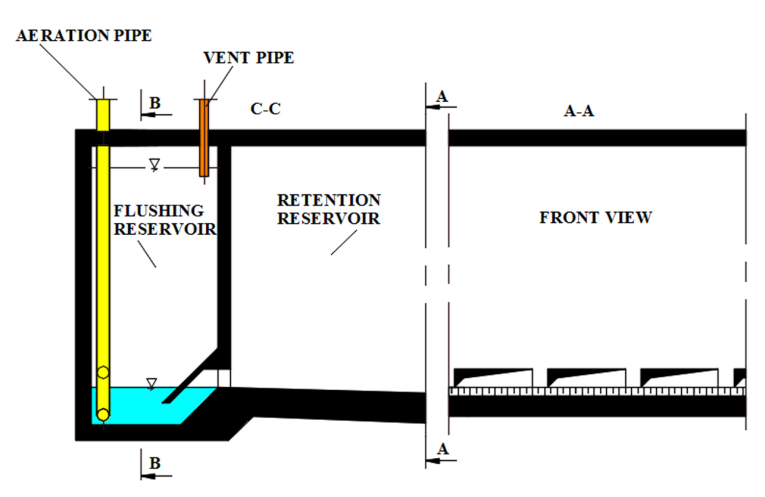

transporting the excess air is carried out via the vent pipe located in the roof (Fig. 2).

The process of reservoir flushing and, therefore, the outflow of water from flushing reservoir occurs when the retention reservoir is entirely emptied, and, using the vent pipe, the air negative pressure over the water surface in the flushing reservoir is equal to the atmospheric pressure.

The end of the vent pipe is installed in a point of the outflow stream where the biggest values of negative pressure occur (Figs. 3 and 4). This solution accelerates the rise of the water surface in the flushing reservoir compared to the retention reservoir.

The vent pipe should represent a separate installation in order for it to act as a lever during the emptying of the retention reservoir. During the filling of the retention and flushing reservoir in a separate vent installation, the air is compressed, thus effectively preventing from its filling with water.

The working principle of the air flow system is presented in Figures 5 and 6.

b)

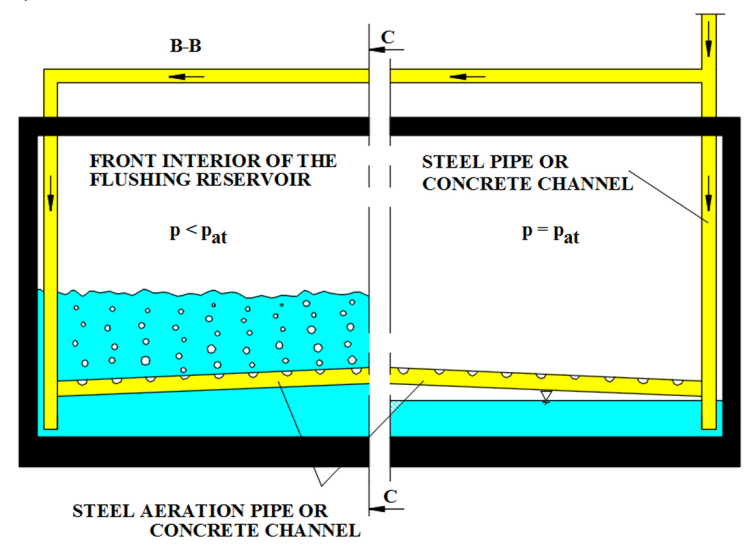

Fig. 2. Design of the flushing reservoir

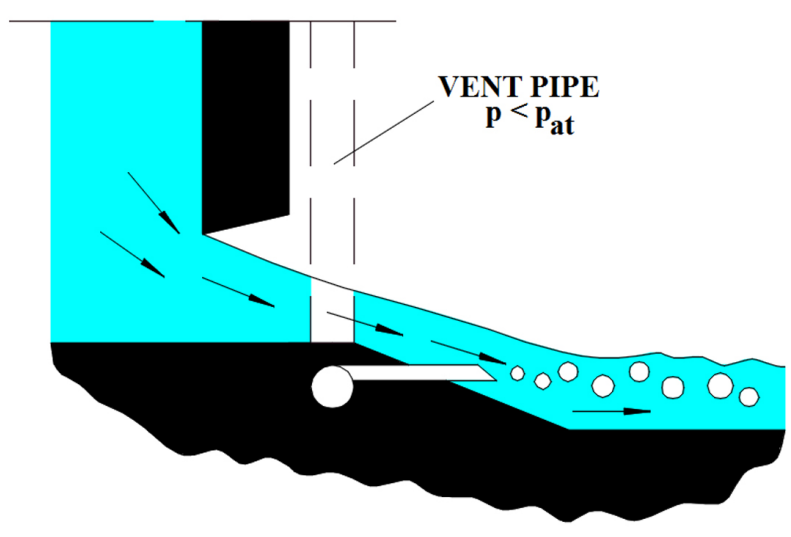

Fig. 3. Installation of the tip of the vent pipe at free flow 

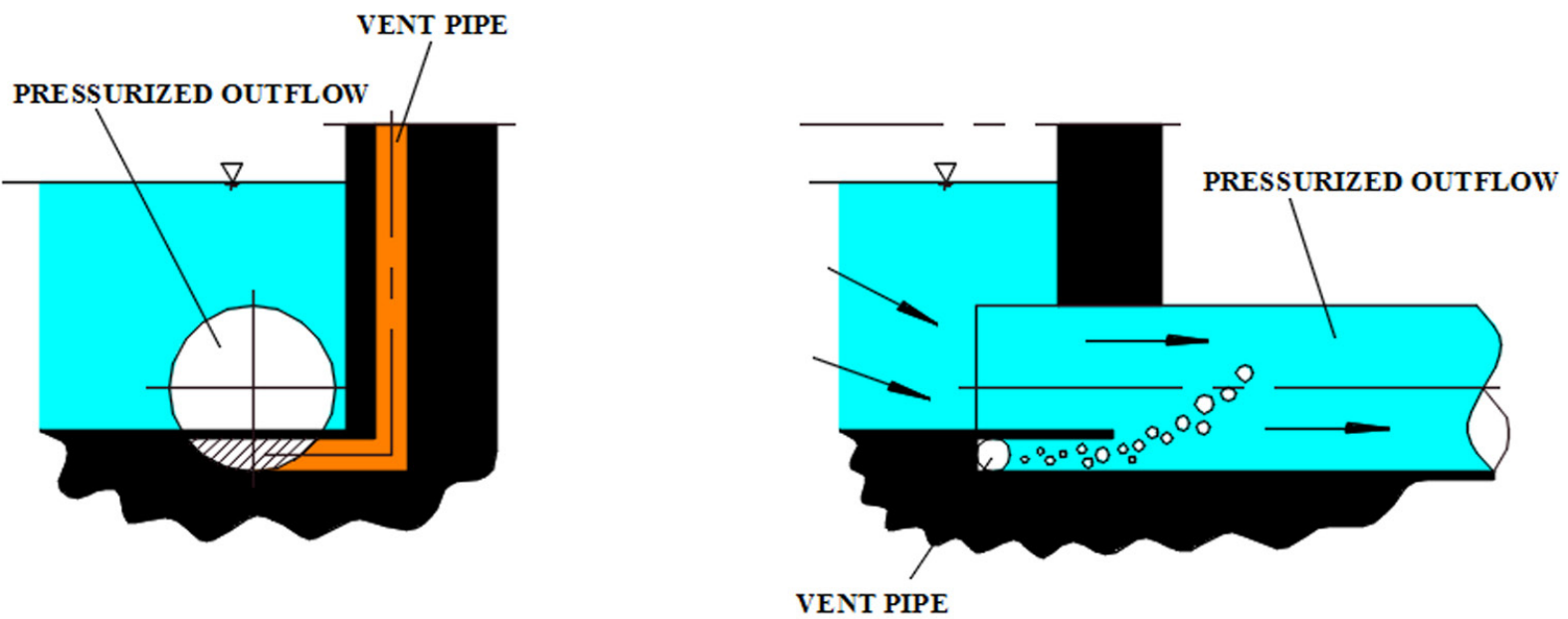

Fig. 4. Installation of the tip of the vent pipe with pressurized emptying of the conventional retention reservoir

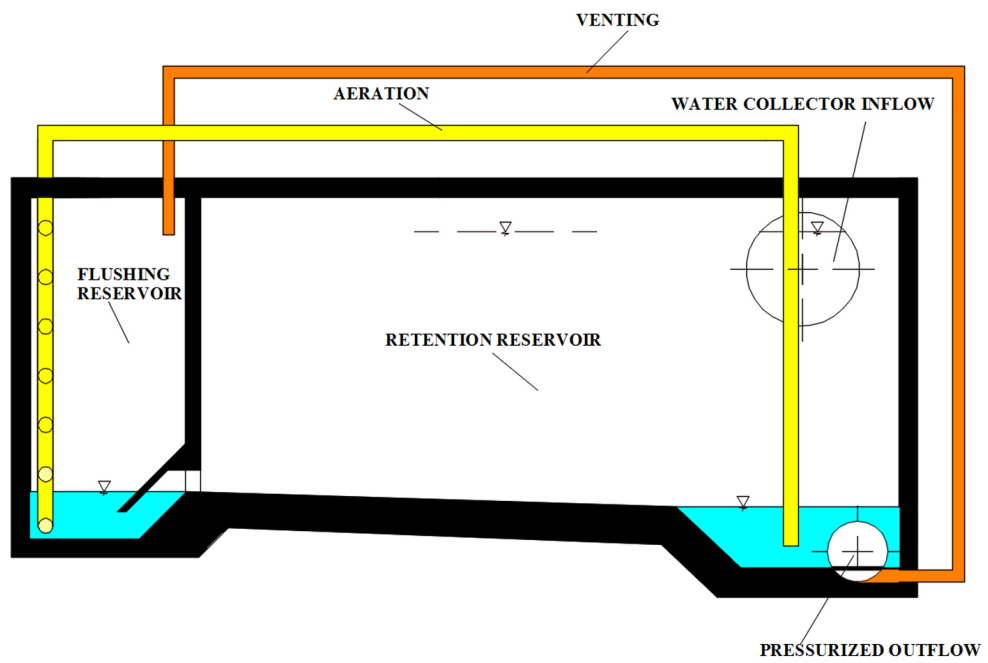

Fig. 5. Functional diagram for the air flow system in conventional retention reservoirs

\section{WORKING PRINCIPLE OF THE FLUSHING RESERVOIR}

The retention reservoir, composed of two gravitational chambers, with one of them being flow chamber with low volume compared to the second chamber (retention chamber), is equipped in the flushing container separated from the part of the retention chamber. Filling the flushing chamber occurs using the principle of communicating vessels through the niche on the bottom between the flushing and retention chambers. With this basic version of the container, the vent pipe and aeration pipe are the components of the same venting and aeration system. This solution is less efficient than the proposed one, but represents the idea of operation of such systems [Malmur et al., 2008].

The inlet to the venting and aeration system is located in the roof of the flushing chamber. The tips of the aeration and vent pipes are installed near the bottom of the retention chamber and in the well (in the standing water) after the outlet hole.

If the inflow of sewage to the flow chamber is greater than its outflow, the chamber is filled. The atmospheric pressure is present in all three chambers of the reservoirs (Fig. 7a). After filling the flow chamber, the sewage overflows the overflow edge infiltrating into the retention chamber through the niche to the flushing chamber. The sewage surface in the submerged vent pipe and the flushing chamber are at the same level, lower than the sewage surface in the retention chamber. The difference $\left(h_{x}\right)$ is equal to the submersion depth of the outlet of the vent pipe (Fig. 7b). The retention chamber is filled until the sewage surfaces are equal in the flow and retention chambers (Fig. 7c). At this point, the flap valve installed in the bottom part of the overflow edge that sepa- 


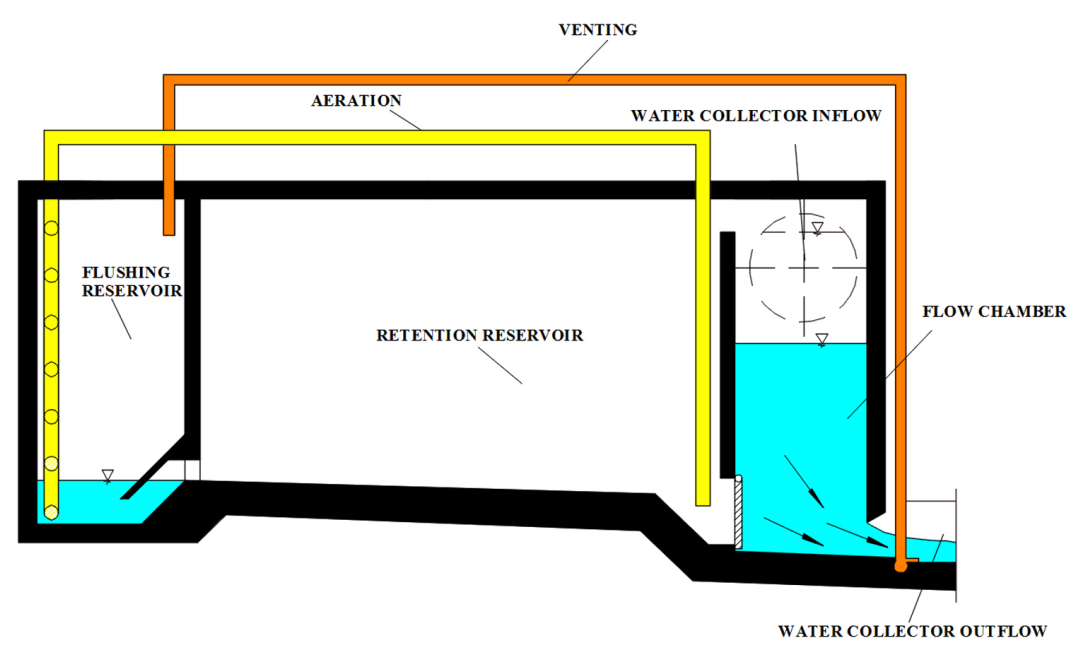

Fig. 6. Functional diagram for the air flow system in the CONTRACT type reservoir with pressure-free outflow

a)

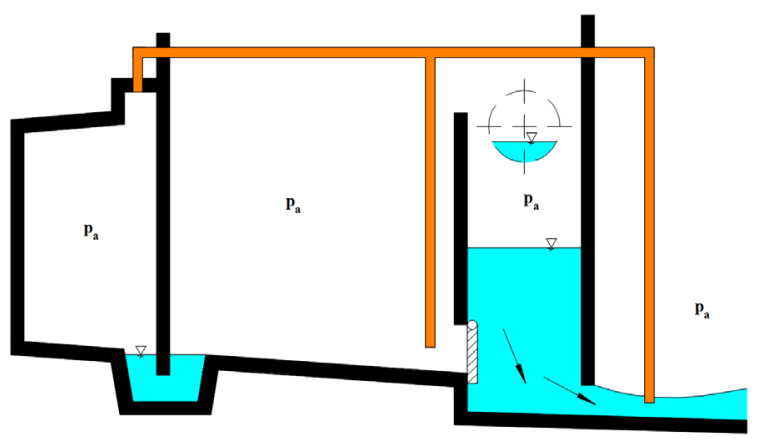

c)

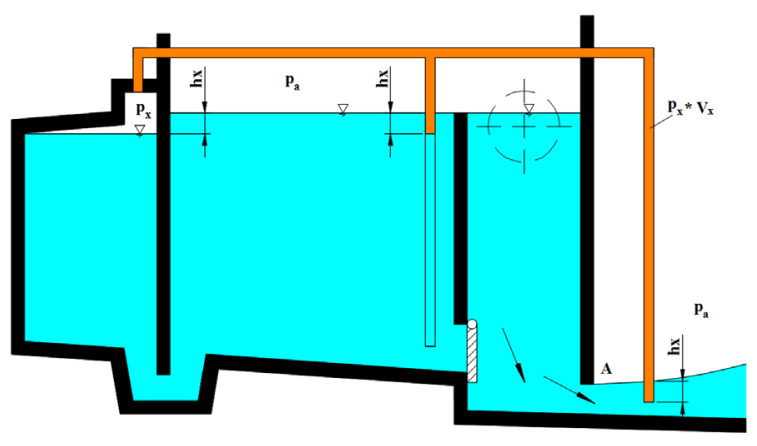

b)

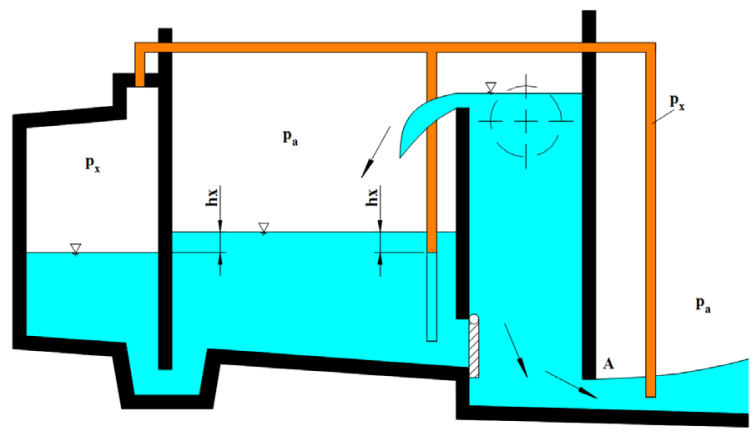

d)

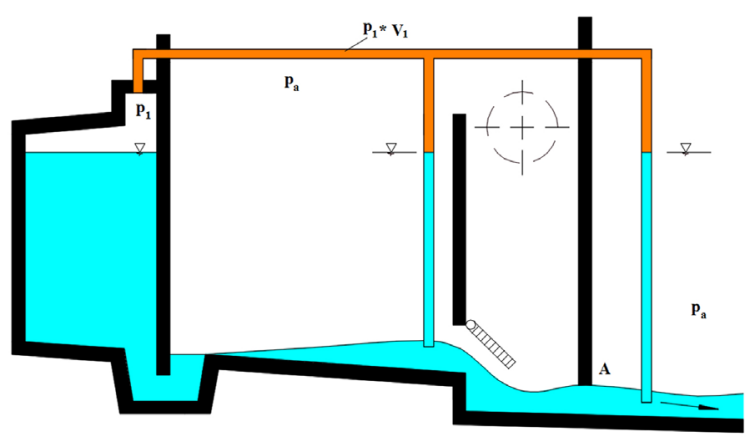

Fig. 7. Phases of operation of the flushing reservoir

rates both chambers of the reservoir opens automatically due to the difference in the hydrostatic pressures. It allows for the flow of sewage only in the direction from the retention chamber to the flow chamber. During the emptying of the reservoir, the level of sewage in the flushing chamber is slightly lowered (Fig. 7d) and the negative pressure sucks the sewage to the vent pipe. After the retention chamber is entirely emptied, the sewage is discharged from the vent pipe and the flushing process starts.

\section{SYSTEMS FOR FLUSHING THE RETENTION CHAMBERS}

Previous solutions concerning the method of flushing bottoms of the retention chambers of the reservoirs worked automatically and offered high efficiency and effectiveness of operation [Kisiel et al., 2008; Malmur et al., 2008]. Therefore, they can be recommended for the use in engineering practice. From the hydraulic standpoint, one should emphasize the following aspects: 
- in the process of emptying the flushing chamber, the maximal outflow velocity of the flushing stream of liquid is at the initial point when the chamber filling is the biggest. This speed decreases with the reduction in the level of liquid surface in the chamber, substantially reducing the flushing efficiency of the fluid stream.

- due to the decreasing velocity of the fluid outflow from the chamber, the emptying process time is elongated, so that in the final phase the flushing effect is lost.

These observations show that the effective flushing of the retention chamber bottom should be performed in the initial phase of emptying the flushing chamber.

In the solutions presented in the study, the bottom of the flushing chamber is located below the maximal filling of the retention chamber of the reservoir (Fig. 8 and Fig. 9). Consequently, in the final phase of emptying this flushing chamber, the outflow velocity of the fluid is similar to the initial phases in the chamber, the bottom of which is at the level of the flushed bottom of the reservoir retention chamber.

\section{GRAVITY FLUSHING CHAMBER}

The retention reservoir (Fig. 8), designed for the stormwater system and the combined sewer system, contains the flow chamber (KP) and gravity retention chamber (KRG). They are separated from each other with the partition wall with overflow edge (PSZ). An outflow hole with a check valve (KL) is located at the bottom zone of the gravity retention chamber (KRG), automatically opened towards the flow chamber (KP). In the upper part, the flow chamber (KP) is equipped in the inflow collector $(\mathrm{KD})$ that supplies sewage to the reservoir, whereas in the lower part, it contains a sewage outflow hole connected with the outflow collector (KO). A flushing chamber (KPŁ) is located inside the retention chamber (KRG), with its bottom is situated at the level over the sewage surface in the entirely filled retention chamber (KRG). In practice, if field conditions are suitable, the flushing chamber (KPŁ) can be located outside the vertical projection of the reservoir. It should also be noted that the capacity of the flushing chamber is included in the total retention capacity of the reservoir.

The flushing chamber (KPŁ) and retention chamber (KRG) are connected with the discharge channel (PZ) adjacent to the wall of the reservoir which is located opposite to the outlet hole (KL). The flushing channel is connected with the discharge channel (PZ) through the overflow pipe $(\mathrm{PN})$ and outlet valve $(\mathrm{Z})$ in the bottom zone. Furthermore, the discharge channel (PZ) is connected through a gap in the bottom zone with the retention chamber (KRG). The flushing chamber (KP€) is open to the atmosphere through a vent (W) which allows for venting the air from the flushing chamber during its filling and inflow of air from the atmosphere during its emptying. Filling the flushing chamber occurs through suction and forcing pump (P).

The sewage supplied to the reservoir through the inflow collector (KD) gradually fills the overflow chamber (KP) and, after reaching adequate

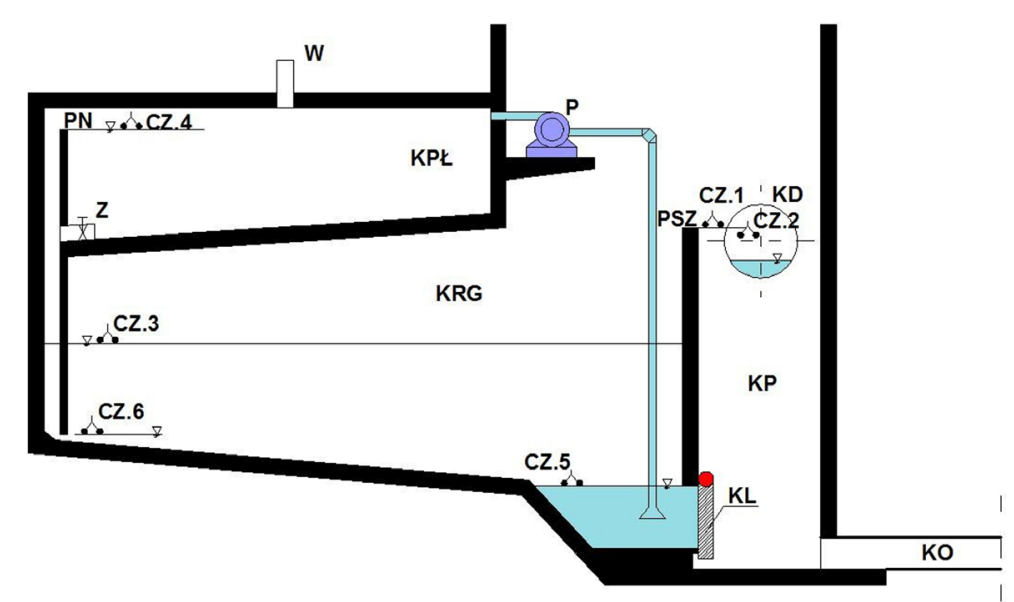

Fig. 8. Diagram of the gravity chamber for flushing the bottom of the retention chamber immediately after emptying from accumulated sewage 
filling level, is transported through the overflow edge (PSZ) to the retention chamber (KRG). With gradual reduction in the sewage inflow, the reservoir starts to be emptied. This is signalled by the integrated CZ.1 and CZ.2 sensors located at the level slightly below the top part of the overflow wall (PSZ) in the flow chamber (KP). When sewage reaches the level of the integrated CZ.1 and CZ.2 sensors, it switches off the pump (P) and starts filling the volume of the flushing chamber (KPŁ). Switching on the pump (P) leads to shutting the outlet valve $(Z)$ in the flushing chamber (KPL). Shutting off the pump (P) occurs after completion of filling of the flushing chamber (KPŁ), which is signalled with the sensor (CZ.4) situated at the level of the top of the overflow wall (PN). Switching off the pump will also occur at the moment of emptying of the retention chamber, i.e. when the filling reaches the level of the CZ.5 sensor. At this point filling of the flushing chamber (KPŁ) will be incomplete. When the fluid stops flowing into the reservoir and the filling level in the flow chamber (KP) is decreased, the contacts of the integrated CZ.1 and CZ.2 sensors are exposed and the power supply for the pump is cut off.

The process of empting the reservoir occurs with the emptying of its gravity chambers (KP) and (KRG). At the point of nearly total emptying of the retention chamber (KRG), when sewage surface reaches the position of the sensor (CZ.5), the process of flushing the bottom of the retention chamber is started through the opening of the valve $(\mathrm{Z})$ and switching on the pump (P), if it continues operation. The contaminants settled on the bottom of the retention chamber are flushed to the outlet hole (KL) and further to the outlet collector (KO). If, during the flushing, the retention chamber (KRG) is filled to the level of CZ.6 sensor situated at the level of outflow of sewage from the discharge channel (PZ) that signals entire covering of the bottom of the retention chamber (KRG) with sewage, the valve $\mathrm{Z}$ is closed and the flushing process is brought to a standstill. After another emptying of the retention chamber (KRG), the signal from the CZ.5 sensor opens the valve (Z) again and flushing is resumed. The process is repeated until the flushing chamber (KPL) is entirely emptied. The CZ.1 and CZ.2 sensors are integrated, which means that the power supply to the relay coils depends on the state of contacts of the relays. The only opening of the contacts of both relays for the CZ.1 and CZ.2 sensors can lead to the conditional opportunity of supplying the power to the pump (P). As mentioned before, the precondition for starting the pump $(\mathrm{P})$ is submersion of the CZ.3 sensor in the sewage of the retention chamber. The CZ3 sensor causes the opening of the contacts of its respective relay, which is maintained by the closed contacts at the relay assigned to the CZ.5 sensor. This means that the pump (P), if it is not switched off by the signal of the CZ.4 sensor, will be switched off using the CZ.5 sensor with opening of the outlet valve $(Z)$, which initiates the process of bottom flushing in the emptied retention chamber (KRG). The pair of integrated CZ.1 and CZ.2 sensors prevents from repeated switching on and off the relay of pump power supply caused by waving of sewage surface in the flow chamber (KP). Furthermore, the integration of the relays of the CZ.3 sensor with the CZ.5 sensor ensures operation of the pump (P), despite surfacing of the CZ. 3 sensor from sewage.

The flushing chamber located at the level of maximal filling the retention chamber ensures high efficiency of the process of flushing the bottom of the retention chamber, since the velocity of the stream of fluid flowing out on the flushing surface is large, even at the final stage of emptying of the flushing chamber. As in all solutions of flushing, the capacity of the flushing chamber is added to the total retention capacity of the reservoir. The location of the CZ.5 and CZ.6 sensors at the bottom of the retention chamber allows for starting the cycle of multiple flushing. Furthermore, the location of the CZ.3 sensor in the retention chamber on the adequate level from its bottom depends, among other things, on the capacity of the flushing chamber. The control over the emptying of the flushing chamber can be changed so that the process of flushing the bottom of the retention chamber occurs at all times, even at a minimal filling.

\section{GRAVITY AND VACUUM CHAMBER FOR FLUSHING}

The liquid reservoir (Fig. 9) contains the flow chamber (KP) with the inlet hole (KD) and outlet hole (KO) as well as the gravity retention chamber (KRG), separated from each other with the partition wall with overflow edge (PSZ). An outflow hole with check valve (KL) is located at the bottom zone of the gravity retention chamber, automatically opened towards the flow chamber 


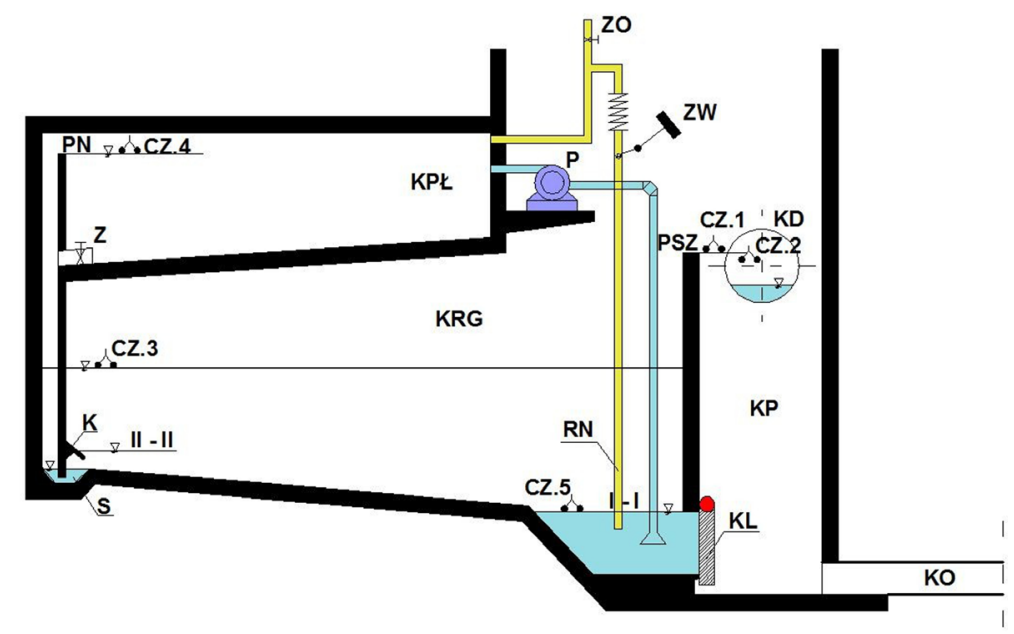

Fig. 9. Design of gravity and vacuum chamber for flushing the bottom of the retention chamber immediately after emptying from accumulated sewage

(KP). A closed flushing chamber is located inside the retention chamber (KRG), with its bottom situated at the level of liquid surface in the entirely filled retention chamber. The flushing chamber (KPŁ) and retention chamber (KRG) are connected with the discharge channel (PZ) adjacent to the wall of the retention chamber which is located opposite the outlet hole (KL). The flushing channel is connected with the discharge channel (PZ) through the overflow pipe (PN) and the outlet valve $(\mathrm{Z})$ in the bottom zone. Furthermore, the discharge channel (PZ) is connected with the drain trap $(\mathrm{S})$ in the bottom zone with the retention chamber (KRG). Its outflow is also equipped in the guide $(\mathrm{K})$ that guides the flushing stream to the bottom of the retention chamber. The flushing chamber (KPŁ) is filled with the suction and forcing pump, with its suction tip located in the retention chamber (KRG) below the level of its bottom in the check valve zone (KL). The under-top zone of the flushing chamber (KPŁ) is connected with the atmosphere through the vent valve ( $\mathrm{ZO})$ and the aeration pipe $(\mathrm{RN})$ equipped in the vertical motion support system (ZW). The inlet to the aeration pipe is situated in the retention chamber $(\mathrm{KRG})$ in the check valve zone (KL). The operation of the pump (P) and valves $(\mathrm{Z})$ and $(\mathrm{ZO})$ is controlled by the signals from the liquid level sensors in the container chambers. The system of chambers in the reservoir is consistent with the solution presented in the patent application from the year 2005. However, the solution employed in this research differs substantially in the method of hydraulic control of the flushing of the bottom of the retention chamber.
The sewage flowing to the reservoir through the inflow collector (KD) gradually fills the flow chamber (KP) and retention chamber (KRG) through the top overflow wall (PSZ). Completion of the sewage accumulation process in the retention chamber (KRG) occurs at their gradual decrease in the flow to the reservoir. This is signalled by the CZ.1 and CZ.2 sensors located at the level, and slightly below, the top part of the overflow wall (PSZ) in the flow chamber (KP). Reaching the level of the integrated CZ.1 and CZ.2 sensors during the process of flow chamber (KP) filling, switches on the power supply for the pump resulting from the immersion of the CZ.3 sensor in the accumulated sewage. Switching on the pump $(\mathrm{P})$ and filling the volume of the flushing chamber (KPE) occurs in the retention chamber. Switching off the pump occurs after the completion of the flushing chamber (KPŁ) filling through the CZ.4 sensor relatively after reaching the waste level I-I in the retention chamber that is after its emptying, signalled by the CZ.5 sensor. If the liquid stops flowing into the reservoir and the filling level in the flow chamber (KP) is decreased (exposing the integrated CZ.1 and CZ.2 sensors), the power supply for the pump is cut off.

The start of the pump (P) is closely related to the necessary shutting of the outlet valve $(\mathrm{Z})$ and opening the vent valve ( $\mathrm{ZO}$ ). Emptying of the reservoir chambers i.e. flow chamber (KP) and retention chamber (KRG) occurs simultaneously. Switching off the pump (P) leads to the negative pressure in the flushing chamber (KPŁ), since the vent valve $(\mathrm{ZO})$ is shut and the outlet valve $(\mathrm{Z})$ is open at the same time. The level of the negative 
pressure closed in the flushing chamber (KPŁ) equals the atmospheric pressure minus the current difference in the levels of sewage in the flushing chamber and the retention chamber. Therefore, the maximum value of the negative pressure in the flushing chamber (KPŁ) is reached at the moment of completion of the retention chamber (KRG) emptying. Furthermore, the increasing level of the negative pressure in the flushing chamber (KPŁ) also leads to suction of sewage to the aeration pipe (RN) until the level of sewage surface reaches the level in the flushing chamber. The aeration pipe $(\mathrm{RN})$ is equipped with an elastic joint and the unloading assembly. Before flushing is started, the aeration pipe, containing the sucked sewage, is heavier and its outlet is immersed to the desired depth.

When the waste level in the retention chamber (KRG) drops below I-I, the aeration pipe (RN) is exposed, and after discharge of the sewage from its interior, it is lifted by the support system up to the level II-II as it becomes lighter. The air starts to flow in from the atmosphere to the flushing chamber (KPŁ), causing its intensive emptying by the opened valve ( $Z$ ). The sewage flowing out of the flushing chamber (KPŁ) through the discharge channel (PZ) to the retention chamber (KRG) flushes the contaminants settled on the bottom, which, are transported to the outflow collector (KO) through the output hole with the flap valve (KL). Filling the retention chamber (KRG) to the level II-II in the process of flushing closes the air supply to the pipe (RN), thus stopping the outflow of sewage from the flushing chamber (KPŁ). The sewage sucked again into the pipe (RN) lower the position of its inlet below the level I-I. Resuming the bottom flushing process occurs, similarly to the previous case, after the level of sewage in the retention chamber (KRG) drops to the level I-I.

Filling of the flushing chamber in the solution presented in this paper occurs during the emptying of the retention chamber, which allows for partial sedimentation of the solid phase suspended in the liquid. The location of the flushing chamber over the flushed bottom leads to the increase in the kinetic energy of the flushing stream, while the stream of the liquid flowing out of the chamber almost does not limit the flow dynamics during emptying of the flushing chamber as it is the case of popular solutions. This solution increases the capacity of the flushing chamber and allows for repeated flushing of the bottom of the retention chamber with the fluid collected in the flushing chamber, effectively preventing from collection of the contaminants on its bottom. Integration of the CZ.1 and CZ.2 sensors consists in that their relays have mutually current-supported electromagnet coils. This means that cutting off the power supply to the pump occurs only if both sensors stop the operation of both relays. In practice, this means that the support current supplied to the coil of the first relay flows through the closed contacts of the second relay. This integration of the sensors CZ.1 and CZ.2 prevents from unsteady operation of pump control operation caused by undulated surface of the sewage. The CZ.3 sensor, located in the retention chamber allows for supplying current to the coils of the respective sensors CZ.1 and CZ.2. The sensor CZ.3 guarantees switching on the pump only if sewage is accumulated in the retention chamber.

\section{CONCLUSIONS}

1. Previous solutions concerning the methods of flushing the bottom of the retention chamber, with particular focus on the most recent ones, meet the requirements of effective removal of the sludge accumulated in the process of retention of sewage in sewerage reservoirs. It is remarkable that there is no solution for flushing of the vertical walls of the reservoir that would be recommended for the use in practice. The problems of flushing the sewerage reservoirs also have a hygienic aspect connected with epidemiological safety. Therefore, it is essential to continue the research on flushing the sewerage system reservoirs.

2. The systems for flushing the retention chambers presented in the study are presented only as a general idea, rather than a specific technical solution for the problem. Therefore, the design of the flushing system will be individual for any case, with the principles and aim of its operation remaining the same.

3. The increase in the efficiency of flushing can be obtained by a reliable control of hydraulic parameters of the stream that dynamically affects the contaminants present on the bottom of the reservoir. The design of the retention reservoir should take into account the parameters of the flushing chamber with respect to the retention chamber, in order to achieve the effect of double or repeated flushing. Obtaining the effect of repeated flushing is controlled by the 
adoption of the depth of the aeration pipe tip immersion in the retention chamber.

4. The analysis of the hydraulic operation of the presented flushing chamber leads to the conclusion that the most efficient solution is the system where the height of the bottom of the flushing chamber with respect to the bottom of the retention chamber that is cleaned from the sewage sludge is the highest possible. Such relation between the bottoms of the flushing and retention chambers ensures high velocities of the flushing stream, thus enhancing the flushing efficiency and measurably shortening the time of emptying of the flushing chamber.

\section{Acknowledgements}

This scientific study was financed within the research project BSPB-401-301/17.

\section{REFERENCES}

1. Deska I., Ociepa E., Mrowiec M., Łacisz K. 2016. Investigation of the influence of hydrogel addition on the retention capacity of green roofs. Proceed- ings of ECOpole, 10(2), 625-633 (in Polish).

2. Dziopak J. 1990. Highly effective methods flushing bottom of the gravitational of retention chamber sewage tank. Gaz, Woda i Technika Sanitarna, 2-3, 68-70 (in Polish).

3. Kisiel A., Kisiel J., Malmur R., Mrowiec M. 2008. Retention tanks as key elements of modern drainage systems. Czasopismo Techniczne, No. 1-Ś, 18(105), 41-63 (in Polish).

4. Malmur R., Kisiel A. 2008. Flushing out sludge settling at the bottom of retention chambers in sewage reservoirs. Inżynieria i Ochrona Środowiska, 11(3), 269-280 (in Polish).

5. Ociepa E., Mrowiec M., Deska I., Okoniewska E. 2015. snow cover as a medium for deposition of pollution. Rocznik Ochrona Środowiska - Annual Set The Environment Protection, 17(1), 560-575 (in Polish).

6. Wolski P. Wolny L. 2011. Effect of disintegration and fermentation of sewage sludge on susceptibility to dehydration. Rocznik Ochrona Środowiska - Annual Set The Environment Protection, 13, 1697-1706.

7. Zawieja I., Wolski P. 2013. Effect of hybrid method of excess sludge disintegration on the increase of their biodegradability. Environment Protection Engineering, 39(2), 153-165. 